\title{
An exploration of factors influencing workplace learning among novice teachers in Malaysia
}

\begin{abstract}
With the rapid pace of development in Malaysia, workplace learning in the teaching profession is becoming ever more critical as the expectations on both teachers and students continue to rise. Little is known, however, about how novice teachers in Malaysia perceive their work environments from the point of view of learning. In response to this gap, an exploratory study was conducted to develop and conduct preliminary testing of the PFIL (perceptions toward factors influencing workplace learning among novice teachers) inventory. Following survey construction, the 20-item PFIL inventory was tested among 90 recent graduates of one teacher training institute in Sarawak, Malaysia. Exploratory factor analysis resulted in four unique subscales named Personal Attitude, Working Conditions, Learning System and Work Expectations. Descriptive analysis indicated significant differences by sex for the Learning System Subscale and for the Working Conditions and Work Expectations subscales by length of service. Follow-up inquiry calls for expanding the sampling framework throughout Malaysia and conducting confirmatory factor analysis and additional instrument validation on the PFIL.
\end{abstract}

Keyword: Workplace learning; Novice teachers; Teacher professional development; School culture 